\title{
Factors associated with hostility among people living with HIV/AIDS in Northeast China: a cross-sectional study
}

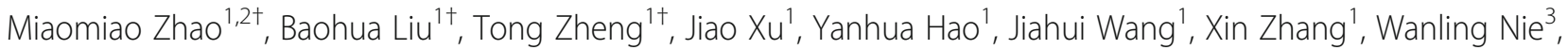
Chao Wang ${ }^{4}$, Fuxiang Wang ${ }^{5}$, Mingli Jiao ${ }^{1}$, Qunhong Wu ${ }^{1 *}$ and Libo Liang ${ }^{1 *}$

\begin{abstract}
Background: Hostility can result in negative outcomes in people living with HIV/AIDS (PLWHA); however, previous research on this topic is far from adequate. To contribute to existing knowledge on this aspect of PLWHA, the current study examined the prevalence of hostility and its potential influencing factors among PLWHA.

Methods: A cross-sectional questionnaire survey was undertaken on 218 HIV patients in Heilongjiang Province of China between March and August in 2013. A multiple logistic regression analysis was performed to identify factors associated with hostility.

Results: The prevalence of hostility was $17.0 \%$ among the participants. The three most alarming types of hostility included desiring to kill the person who infected them, blaming the infection on the society, and abandoning themselves to despair. A multiple logistic regression model identified that depression $(\mathrm{OR}=3.845,95 \% \mathrm{Cl}=1.309-9.229)$, perceived stigma $(\mathrm{OR}=3.281,95 \% \mathrm{Cl}=1.109-7.711)$, and fear of dying $(\mathrm{OR}=2.710,95 \% \mathrm{Cl}=1.068-6.881)$ were the risk factors for hostility, while higher levels of trust-in-doctor $(\mathrm{OR}=0.176,95 \% \mathrm{Cl}=0.060-0.517)$ and per capita household income $(\mathrm{OR}=0.344,95 \% \mathrm{Cl}=0.119-0.991)$ were protective factors.

Conclusions: Our findings highlight the prominent influence of psychological, healthcare, and social factors on hostility among PLWHA. Interventions specifically targeted to reduce hostility should be provided, including incorporating psychological service into HIV management guidelines, enhancing PLWHA's trust-in-doctor, establishing comprehensive services for PLWHA, reducing the social stigma against PLWHA, and paying more attention to PLWHA with financial problems. These interventions may improve the management and control of HIV/AIDS.
\end{abstract}

Keywords: HIV/AIDS, Hostility, Mental health, Depression

\section{Background}

Acquired immune deficiency syndrome (AIDS) is a spectrum of conditions caused by human immunodeficiency virus (HIV), and is considered one of the most serious health and development issues in the world [1]. According to the World Health Organization (WHO), nearly 36.9 million people were living with HIV/AIDS in 2017, including 1.8 million new cases [2]. Despite

\footnotetext{
* Correspondence: wuqunhong@163.com; Ilbhit@163.com

${ }^{+}$Miaomiao Zhao, Baohua Liu and Tong Zheng contributed equally to this work.

${ }^{1}$ Department of Social Medicine, School of Health Management, Harbin Medical University, 157 Baojian Road, Nangang District, Harbin 150081, Heilongjiang, China

Full list of author information is available at the end of the article
}

substantial efforts in tackling the HIV/AIDS epidemic in China, the total number of people living with HIV/AIDS (PLWHA) is still increasing, which is a fact backed up by evidence: the number of PLWHA nearly doubled between 2012 and 2017, going from 385,817 to 758,610 $[3,4]$. This increasing number of HIV cases poses huge challenges to China concerning treatment, care, and support for PLWHA.

The advancements in antiretroviral therapies (ART) have greatly decreased the mortality rates among PLWHA, as well as improved their survival time, which has transformed HIV/AIDS from a terminal illness to a chronic disease [5]. Consequently, PLWHA face more psychological challenges since they need to cope with

(c) The Author(s). 2019 Open Access This article is distributed under the terms of the Creative Commons Attribution 4.0 International License (http://creativecommons.org/licenses/by/4.0/), which permits unrestricted use, distribution, and 
HIV/AIDS during their extended lifetime [6]. For example, since HIV/AIDS is an incurable disease often accompanied by severe symptoms, PLWHA are faced with high risk of death. Further, PLWHA are easily rejected and stigmatized owing to the misconceptions about HIV transmission and disapproved risk behavior among the infected groups such as men who have unprotected sex with men, sex workers and injection drug users [7]. Additionally, PLWHA are more likely to be exposed to a wide variety of stressful situations, including having somatic symptoms, receiving long-term medical treatments, as well as experiencing medication side effects, marital conflicts, job loss and financial problems [8-10]. Such factors are associated with an increased risk of developing psychological disorders such as depression, anxiety, guilt and loneliness [11-13]. Thus, in the absence of support from their social environment or psychological services, PLWHA might turn these internalized negative emotions into hostility towards society [14]. Previous research had corroborated that PLWHA experienced a higher risk of hostility, compared to healthy individuals $[15,16]$.

Hostility can be conceptualized as a negative attitude towards the outside world $[17,18]$, and its impact on a person's life is multifaceted. Previous studies showed that hostility could impact C-reactive protein interleukin, and proinflammatory cytokines to cause inflammation [19-21], which may worsen the physical health of PLWHA. Further, hostility was associated with engagement in risk behaviors, such as injection drug use, unprotected sex and suicide attempts [22, 23]. In addition, hostility could also lead to dire consequences for society because it had relations with aggressive, vengeful, and antisocial behaviors $[24,25]$. In summary, hostility is a potential threat to the health of PLWHA, and to HIV/ AIDS control and social safety.

Prior studies showed that hostility can be changed both through external events and internally adjustments related to somatic or psychiatric symptoms [18]. Therefore, exploring potential factors associated with hostility can play a pivotal role in reducing hostility among PLWHA. In this regard, implementing interventions associated with these factors may be important not only for improving the health of PLWHA, but also for controlling the harmful consequences for society. Despite these potential benefits, there is limited research examining the influencing factors of hostility among PLWHA. To our knowledge, only one previous study had explored the association between perceived stigma and hostility among men who have sex with men (MSM) with HIV/ AIDS and found that the perceived stigma predicted a higher level of hostility [26]. Thus, more researches are needed on the examination of hostility and its influencing factors among PLWHA.
In this study, we aimed to assess the prevalence of hostility among PLWHA, and to explore the multidimensional factors (including sociodemographic characteristics, disease related characteristics, self-reported physical health status, psychological factors, healthcare service factors and social factors) that may influence hostility. Our results could be used as evidence by policymakers and health service providers to improve HIV/AIDS care and intervention programs.

\section{Method}

\section{Study population and data collection}

We conducted a cross-sectional survey among PLWHA in an HIV-designated hospital in Heilongjiang Province between March and August in 2013. Chinese patients who were aged 18 years and above, and diagnosed with an HIV infection were included in this study. During patients' regular hospital visits, all eligible patients were briefed by their physicians on the purpose and value of this investigation. The ones who agreed to participate were referred to the researchers by their physicians. Then, the researchers gave each patient a full explanation regarding the procedures of the study. Voluntary participation was emphasized throughout the study. After signing written informed consent, the participants were asked to complete a self-administrated questionnaire. To ensure quality, a researcher was present during the survey and would provide assistance upon participants' request. The researchers who participated in this process were from Social Medicine Department of Harbin Medical University and had received training on HIV/AIDS related research. All personal identifiers were removed from the questionnaires to ensure confidentiality.

In total, 241 patients were approached during the survey, and all of them agreed to participate in the survey. However, 14 patients dropped out during the investigation because they lacked time to complete this long questionnaire. Afterwards, During subsequent data cleaning process, 9 patients were further excluded owing to missing data (including 3 non-Han ethnic, 2 illiterates and 4 other participants, who were excluded from the sample for further statistical analysis). Finally, 218 participants were involved in this study.

\section{Variables \\ Dependent variable}

Based on previous studies, we believe that the psychological reactions of patients with HIV infection differ from those of other patients or the general population: apart from severe physical health damage, PLWHA also experience stigma and social exclusion. Thus, in this study, we used a hostility questionnaire specifically developed for PLWHA by Meng [27] to estimate 
participants' level of hostility. The questionnaire consists of six items including: "Do you abandon yourself to despair?", "Do you feel like you hate the outside world?", "Do you have a desire to kill the person who infected you?", "Do you blame the infection on society and others?", "Do you feel abandoned by society?", "Do you have the urge to retaliate against society?" Each item was scored on a scale ranging from 1 (never) to 5 (all of the time). The scores of all the six items were taken into average, and a higher average score indicated a higher level of hostility. An average score greater than 2 was drawn as the demarcation criterion for having hostility. The Cronbach's $\alpha$ in the present study was 0.92 , indicating a high internal consistency.

\section{Independent variable}

Sociodemographic data of PLWHA were collected (see Table 1), including gender, age $(<30,31-39,40-49$, or $\geq 50$ years), marital status (married/cohabitating or others), educational status (junior high school and below, senior high school, college, or undergraduate and above) and per capita household income $(\leq 2000$ or $>2000 \mathrm{CNY}$ per month).

Disease related characteristics of the participants were also collected (see Table 1), including infection route (homosexual contact, heterosexual contact, blood, or others), infection duration ( $\leq 1,1-3$ and $>3$ years), and CD $4+$ cell $\left(\leq 200,200-500\right.$ or $>500$ cells $\left./ \mathrm{mm}^{3}\right)$.

To measure the self-reported physical health status of PLWHA, we used the physical health domain of the WHOQOL-HIV-BREF questionnaire, which included four items (pain/discomfort, energy, symptoms and sleep), with a higher score indicating a better physical health status [28]. The Chinese WHOQOL-HIV-BREF had been validated in previous studies for Chinese PLWHA $[29,30]$. The Cronbach's $\alpha$ of these four items was 0.753 in this study. We adopted the mean score as the cut-off score for dichotomization of the physical health status (high level and low level).

Psychosocial factors included depression, anxiety, and a fear of dying. Depression was assessed using Burns Depression Checklist (BDC), consisting of 15 items rated on a scale from 0 (not at all) to 3 (a lot). The total score ranged from 0 to 45 , with a higher score indicating more severe depression [31]. This scale had been previously validated in China [32]. Individuals with a total score equal to or greater than 11 were considered to have depression [33].The Cronbach's $\alpha$ of the BDC scale was 0.96 in the current study. Zung Self-Rating Anxiety Scale (SAS) was used to evaluate the level of anxiety symptoms [34]. It consisted of 20 items rated on a scale ranging from 1 (a little of the time) to 4 (most of the time). The total score ranged from 20 to 80 , which was then transformed to a SAS Index score (raw SAS score multiplied by 1.25). Individuals with a SAS Index score equal to or greater than 50 were considered to have anxiety, and this scale had been widely used and validated in China [35, 36]. The Cronbach's $\alpha$ of the SAS scale was 0.89 in this study. Finally, an individual's fear of dying was measured using one item: "During the disease, did you experience fear of dying?" Participants answered Yes $(=1)$ or No $(=0)$ to this question.

Healthcare service factors included healthcare satisfaction and trust-in-doctor. Health care satisfaction was measured using the question "Are you satisfied with the health care you received?" Participants answered based on a 5point Likert scale ranging from 1 (strongly dissatisfied) to 5 (strongly satisfied). For data analysis, responses were recoded as: "Not Satisfied" (ranging from 1 to 3 ) and "Satisfied" (ranging from 4 to 5 ). To assess patient's trust-indoctor, the Wake Forest Physician Trust Scale (WFPTS) was used [37]. A previous study showed that the Chinese version of the WFPTS had good reliability and validity [38]. This instrument contained 10 items, which were rated on a 5-point Likert scale ranging from 1 (strongly disagree) to 5 (strongly agree), with a higher score indicating a greater trust-in-doctor. We adopted the mean score as the cut-off score for dichotomization of participants' trust (high level and low level). The Cronbach's $\alpha$ of this scale was 0.79 in this study.

Social factors included family and social support, and perceived stigma. The Chinese Family and Social Support questionnaire for PLWHA was used to measure the frequency of family and social support based on a 5point Likert scale ranging from 1 (none of the time) to 5 (all the time), with a higher score indicating a higher level of family and social support for PLWHA [27]. We adopted the mean as the cut-off score for dichotomization of support (high level and low level). In this study, the Cronbach's $\alpha$ of this scale was 0.87 . To assess perceived stigma, the simplified version of Berger HIV Stigma scale was used, with a higher score indicating a higher level of perceived HIV stigma [27]. This scale had been validated in a previous study for Chinese PLWHA [39]. The mean score was adopted as the cut-off score for dichotomization of stigma (high level and low level). This scale had a high internal consistency (Cronbach's $\alpha=0.90)$ in this study.

\section{Statistical analyses}

First, we used descriptive statistics to describe participants' basic characteristics and the prevalence of hostility among PLWHA. Chi-square tests were performed to analyze the differences in hostility across different levels of independent variables. Then, a multiple logistic regression was performed to examine the associations between hostility and its influencing factors among PLWHA (method= ENTER). The independent variables that were found to be 
Table 1 Participants' characteristics and their associations with hostility

\begin{tabular}{|c|c|c|c|c|}
\hline & \multirow[t]{2}{*}{ Total, N (\%) } & \multicolumn{2}{|l|}{ Hostility } & \multirow[t]{2}{*}{$p$} \\
\hline & & Yes, n (\%) & No, n (\%) & \\
\hline \multicolumn{5}{|l|}{ Sociodemographic characteristics } \\
\hline Sex & & & & $0.626^{\mathrm{a}}$ \\
\hline Male & $210(96.3)$ & $35(16.7)$ & $175(83.3)$ & \\
\hline Female & $8(3.7)$ & $2(25.0)$ & $6(75.0)$ & \\
\hline Age (years) & & & & 0.400 \\
\hline$<30$ & $69(31.7)$ & $12(17.4)$ & $57(82.6)$ & \\
\hline $30-39$ & $64(29.4)$ & $7(10.9)$ & $57(89.1)$ & \\
\hline $40-49$ & $53(24.3)$ & $12(22.6)$ & $41(77.4)$ & \\
\hline$\geq 50$ & $32(14.7)$ & $6(18.8)$ & $26(81.3)$ & \\
\hline Marital status & & & & 0.849 \\
\hline Married or cohabitating & $62(28.4)$ & $11(17.7)$ & $51(82.3)$ & \\
\hline Other & $156(71.6)$ & $26(16.7)$ & $130(83.3)$ & \\
\hline Education & & & & 0.256 \\
\hline Junior high school and below & $53(24.3)$ & $13(24.5)$ & $40(77.5)$ & \\
\hline Senior high school & $52(23.9)$ & $9(17.3)$ & $43(82.7)$ & \\
\hline College & 47 (21.6) & $8(17.0)$ & $39(83.0)$ & \\
\hline Undergraduate and above & $66(30.3)$ & $7(10.6)$ & $59(89.4)$ & \\
\hline Per capita household income (CNY) & & & & 0.005 \\
\hline$>2000$ & $105(48.2)$ & $10(9.5)$ & $95(90.5)$ & \\
\hline$\leq 2000$ & $113(51.8)$ & $27(23.9)$ & $86(76.1)$ & \\
\hline \multicolumn{5}{|l|}{ Disease related characteristics } \\
\hline Infection routes & & & & 0.999 \\
\hline Homosexual contact & $149(68.3)$ & $25(16.8)$ & $124(83.2)$ & \\
\hline Heterosexual contact & $28(12.8)$ & $5(17.9)$ & $23(82.1)$ & \\
\hline Blood & $17(7.8)$ & $3(17.6)$ & $14(82.4)$ & \\
\hline Others & $24(11.0)$ & $4(16.7)$ & $20(83.3)$ & \\
\hline Infection duration (years) & & & & 0.796 \\
\hline$\leq 1$ & $80(36.9)$ & $11(13.8)$ & $69(86.3)$ & \\
\hline $1<x \leq 3$ & $82(37.8)$ & $16(19.5)$ & $66(80.5)$ & \\
\hline$>3$ & $55(25.3)$ & $10(18.2)$ & $45(81.8)$ & \\
\hline CD4 + cell (cells/mm3) & & & & 0.669 \\
\hline$\leq 200$ & $83(38.1)$ & $12(14.5)$ & $71(85.5)$ & \\
\hline $200-500$ & $117(53.7)$ & $21(17.9)$ & $96(82.1)$ & \\
\hline$>500$ & $18(8.3)$ & $4(22.2)$ & $14(77.8)$ & \\
\hline Self-reported physical health status & & & & 0.004 \\
\hline High & $123(56.4)$ & $13(10.6)$ & $110(89.4)$ & \\
\hline Low & 95 (43.6) & $24(25.3)$ & $71(74.7)$ & \\
\hline \multicolumn{5}{|l|}{ Psychological factors } \\
\hline Depression & & & & 0.000 \\
\hline Yes & $104(47.7)$ & $29(27.9)$ & $75(72.1)$ & \\
\hline No & $114(52.3)$ & $8(7.0)$ & $106(93.0)$ & \\
\hline
\end{tabular}


Table 1 Participants' characteristics and their associations with hostility (Continued)

\begin{tabular}{|c|c|c|c|c|}
\hline & \multirow[t]{2}{*}{ Total, N (\%) } & \multicolumn{2}{|l|}{ Hostility } & \multirow[t]{2}{*}{$p$} \\
\hline & & Yes, n (\%) & No, n (\%) & \\
\hline Anxiety & & & & 0.007 \\
\hline Yes & $103(47.2)$ & $25(24.3)$ & $78(75.7)$ & \\
\hline No & $115(52.8)$ & $12(10.4)$ & $103(89.6)$ & \\
\hline Fear of dying & & & & 0.001 \\
\hline Yes & 77 (35.3) & $20(26.0)$ & $57(74.0)$ & \\
\hline No & $141(64.7)$ & $17(12.1)$ & $124(87.9)$ & \\
\hline \multicolumn{5}{|l|}{ Healthcare service factors } \\
\hline Satisfaction with healthcare & & & & 0.026 \\
\hline Yes & $146(67.6)$ & $18(12.3)$ & $128(87.7)$ & \\
\hline No & $70(32.4)$ & $17(24.3)$ & $53(75.5)$ & \\
\hline Trust-in-doctor & & & & 0.009 \\
\hline High & $119(54.6)$ & $13(10.9)$ & $106(89.1)$ & \\
\hline Low & $99(45.5)$ & $24(24.2)$ & 75 (75.8) & \\
\hline \multicolumn{5}{|l|}{ Social factors } \\
\hline \multicolumn{5}{|l|}{ Family and social support } \\
\hline High & $134(61.5)$ & $17(12.7)$ & $117(87.3)$ & 0.033 \\
\hline Low & $84(38.5)$ & $20(23.8)$ & $64(76.2)$ & \\
\hline Perceived stigma & & & & 0.014 \\
\hline High & $138(63.3)$ & $30(21.7)$ & $108(78.3)$ & \\
\hline Low & $80(36.7)$ & $7(8.8)$ & $73(91.3)$ & \\
\hline
\end{tabular}

${ }^{\mathrm{a}}$ Fisher's exact test

associated with hostility in the Chi-square tests $(p<0.05)$ were entered into the logistic regression, and sociodemographic characteristics were also controlled. All data were analyzed using SPSS 21.0, and $p<0.05$ was considered significant.

\section{Results}

\section{Participants' characteristics}

Of the 218 participants, the majority (96.3\%) were male and most $(85.3 \%)$ were 49 years or below. About threefourths of the participants had finished high school (75.7\%). Less than one-third (30.3\%) were currently married, and less than half $(48.2 \%)$ had a per capita household income over $2000 \mathrm{CNY}$ per month.

The main route of infection was sexual contact (81.2\%). Most participants (91.7\%) had CD4 count less than or equal to 500 cells $/ \mathrm{mm}^{3}$, and the average duration of the infection was 2.2 years. More than half (56.4\%) of the participants reported high level of physical health. In addition, 47.7 and $47.2 \%$ of the participants suffered from depression and anxiety respectively, and $35.3 \%$ reported fear of dying. More than half of the participants reported a high level of trust-in-doctor, family and social support, and perceived stigma (54.6, 61.5 and $63.3 \%$, respectively) (see Table 1).

\section{Prevalence of hostility among PLWHA}

Of the 218 PLWHA, 37 (17.0\%) reported hostility towards society. Chi-square tests showed that hostility was significantly positively associated with depression, anxiety, fear of dying and perceived stigma, and negatively associated with per capita household income, selfreported physical health status, satisfaction with healthcare, trust-in-doctor, family and social support $(p<0.05)$. Participants who had a higher per capita household income, higher level of trust-in-doctor and family and social support, better physical health status, and were satisfied with healthcare were less likely to develop hostility. While those who had depression, anxiety, fear of dying, and higher level of perceived stigma were more likely to develop hostility (see Table 1).

\section{Comparison of the hostility items scores between hostile} and non-hostile PLWHA

We compared the mean scores for each item in the hostility questionnaire between the hostile and non-hostile PLWHA. The results showed that mean scores for all the items among the hostile PLWHA were significantly higher than those among the non-hostile PLWHA (Wilcoxon's rank sum test). Of all the items, the hostile group had the highest mean score for 
"desiring to kill the person who infected them" $(3.86 \pm 1.11)$, followed by "blaming the infection on society and others" (3.46 \pm 1.36$)$, "abandoning themselves to despair" $(3.30 \pm 1.29)$ and "hating the outside world" (3.16 \pm 1.19$)$, whereas the non- hostile group's mean scores were less than 2 for all items. Fortunately, among both groups, the mean score for "intension to retaliate against society" were the lowest (see Fig. 1).

\section{Factors associated with hostility in logistic regression}

Independent variables that were significantly associated with hostility in the univariate analysis were entered into a logistic regression model. In addition, sociodemographic characteristics including sex, age, marital status and education were also controlled in the analyses (these four control variables were not significant; for brevity, we shall not present the results of control variables). Results showed that five factors were significantly associated with hostility among PLWHA. PLWHA who experienced depression were 3.845 times (95\% CI 1.309 to 9.229) more likely to develop hostility than those without depression. Further, PLWHA who reported a high level of perceived stigma were 3.281 times (95\% CI 1.109 to 7.711) more likely to develop hostility than those who reported a low level of perceived stigma. PLWHA who reported a fear of dying were 2.710 times (95\% CI 1.068 to 6.881) more likely to develop hostility than those who did not. In addition, a high level of per capita household income (OR $=0.344,95 \% \mathrm{CI} 0.119$ to 0.991$)$ and trustin-doctor $(\mathrm{OR}=0.176,95 \% \mathrm{CI} 0.060$ to 0.517$)$ could significantly reduce the risk for hostility (see Fig. 2).

\section{Discussion}

This study contributed to the existing knowledge on hostility among PLWHA and its influencing factors. Results showed that $17.0 \%$ of the participants experienced hostility towards society. Further, this rate was higher than that in a previous study conducted in Nigeria, which showed a prevalence rate of hostility was $15.0 \%$ among PLWHA [40]. PLWHA who were depressed, had a fear of dying, and had a higher level of perceived HIV stigma were at higher risk for hostility, while those who had a higher level of trust-in-doctor and per capita household income were at lower risk. This finding is important for health professionals in planning targeted intervention strategies to help mitigate hostility among PLWHA.

Regarding the specific types of hostility, the three most alarming types included "desiring to kill the person who infected them", "blaming the infection on society and others", and "abandoning themselves to despair". It is noteworthy that the mean scores for "desiring to kill the person who infected them" and "blaming the infection on society and others" - reflecting how PLWHA hold external and other factors such as the society and other person who infected them responsible for their infection and disease - were nearly 4 (in a maximum of 5). HIV diagnosis could be extremely distressing [41], and that it was common for patients to not accept the fact of their infection, to consider that they are victims, and to further blame other people or society for their situation [42]. Cherilyn and Clement indicated that PLWHA who blamed others for their HIV infection might also have the feeling of inequity or anger (i.e., they believed that they did not deserve to be infected), and if they were unable to redress the situation, they could transfer these feelings directly to the person who infected them, or even to those unrelated with the infection [43, 44]. This might pose a threat to the safety of the society, and warrant greater attention and further investigation.

In this study, depression was the strongest variable associated with hostility. PLWHA with depression were nearly four times more likely to develop hostility, compared to those without depression. Indeed, depression was considered as one of the most common mental health conditions experienced by PLWHA $[45,46]$, and this study partially corroborated to that notion as data

Abandoning themselves to despair

Hating the outside world

Desiring to kill the person who infected them

Blaminge the infection on society and others
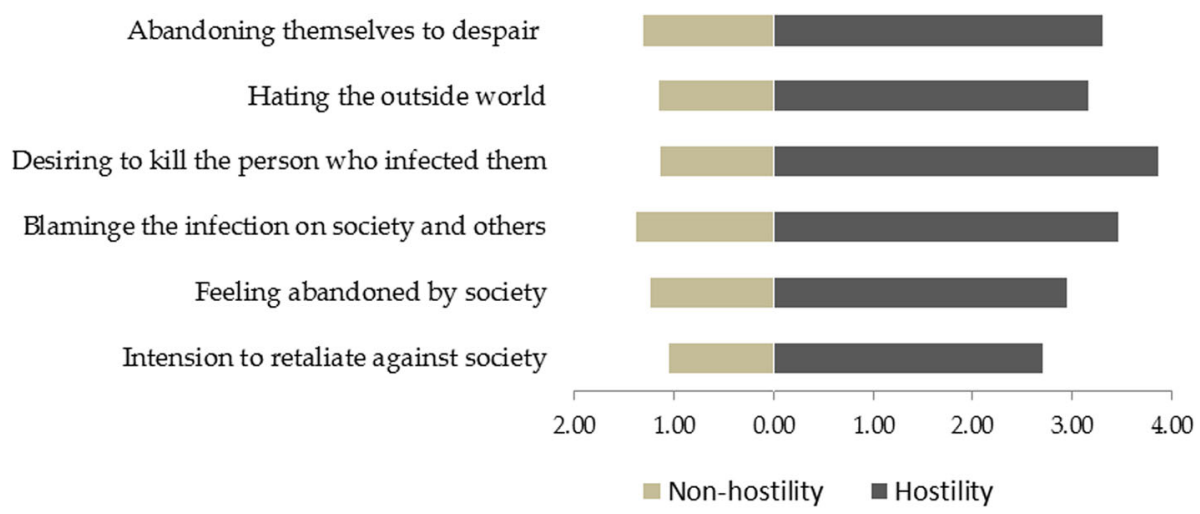

Fig. 1 Scores of specific hostility items among hostile and non-hostile PLWHA 


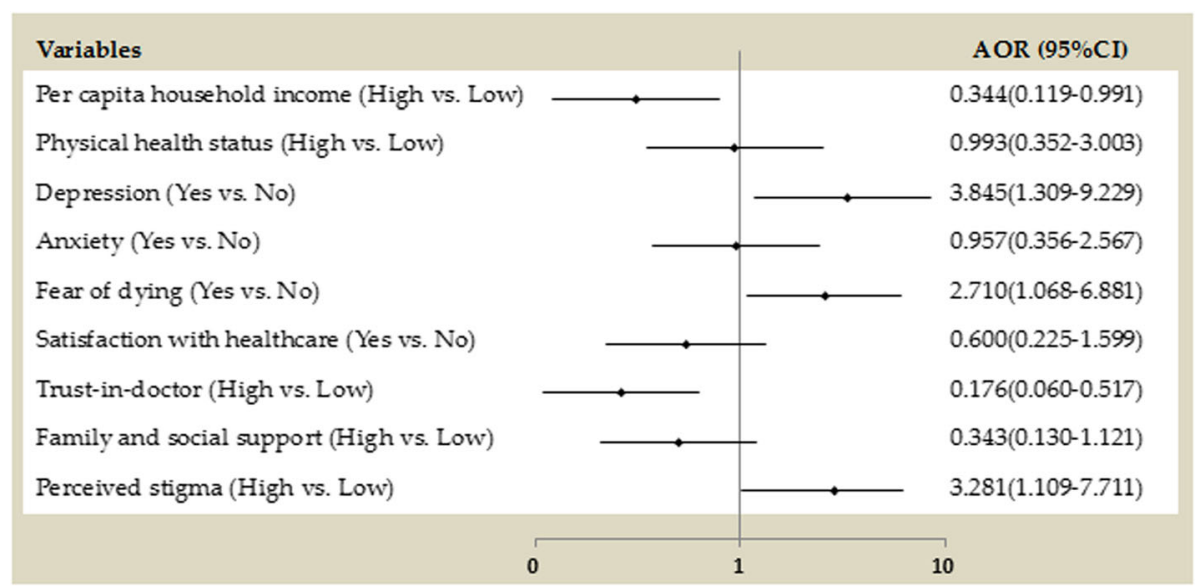

Fig. 2 Factors associated with hostility in logistic regression model

analysis showed that $47.7 \%$ of PLWHA suffered from depression. Liu's study showed that the prevalence of depression might be even higher (60.6\%) among Chinese PLWHA [47]. Depression might be related to hostility for the following reasons. First, depression is commonly accompanied by other symptoms such as anger or irritability [48-50]; a persistent or frequent feeling of anger might be highly associated with or even be regarded as hostility [51]. Second, it is possible that depressed individuals encounter more barriers in achieving healthy emotion regulation, which could evoke more negative emotions [52]. Third, depression also could serve as a moderating factor for social disorder and hostility [25]. Thus, successful management of depression is a key to mitigating hostility among PLWHA. However, the majority of services provided by China Four Frees and One Care Program focus primarily on physical rather than psychological symptoms; indeed, PLWHA are not adequately screened or treated for psychological problems. Therefore, development of regular psychological healthcare services for PLWHA is urgently needed. This action may have additional benefits that go beyond reducing hostility-it may help patients better adhere to their ART medications and improve treatment retention, which are critical to achieving the WHO's 90-90-90 global targets.

In this study, as many as $63.3 \%$ of the participants reported a high level of perceived stigma, indicating that despite many years of effort and campaign for anti-discrimination, social stigma against PLWHA is still a serious concern in China. PLWHA are highly discriminated against in China, partly because the HIV-related risk behaviors such as homosexuality, commercial sex or drug abuse are not accepted by sociocultural norms [53, 54]. Supporting this assumption, a study conducted in China reported that over 90\% of PLWHA perceived HIV-related stigma [55]. Widespread stigmatization and discrimination against PLWHA might in turn trigger PLWHA to be dissatisfied with or resentful against society $[26,56]$. In this study, we found that perceived stigma was the second highest contributing factor for hostility. PLWHA with a higher level of perceived stigma were 3.281 times more likely to develop hostility. Currently, advancements in public health programs to address stigma have been comparatively slow and unsystematic in China [57]. Thus, media publicity and educational strategies aimed at converting and mitigating misunderstanding and fear of HIV/AIDS among the public could help reduce social stigma against PLWHA, thereby reducing hostility among PLWHA.

In this study, one-third of PLWHA reported a fear of dying, which was also significantly associated with hostility. PLWHA with a fear of dying were 2.710 times more likely to develop hostility than those without this fear. As there is currently no definite cure for HIV/AIDS, it is not surprising that it evokes the fear of dying. Fear of dying not only revealed psychological stress on PLWHA [58], but also predicted difficulties in coping with stressful events $[58,59]$. These facts might explain the association between fear of dying and a higher risk for hostility; however, further analyses are needed to confirm this relationship.

Regarding the healthcare service related factors, a higher level of trust-in-doctor stood out as an important protective factor for hostility. PLWHA with higher trust in their doctors were less likely to experience hostility, compared to those with lower trust. Due to discrimination and stigma, it could be particularly difficult for PLWHA to disclose their infection to friends, family, and sex partners $[60,61]$. Additionally, it had been reported that non-disclosure was associated with lower levels of social support [62]. In this context, PLWHA usually regard their doctors whom they can discuss their situation with as a crucial part of their social support 
networks [63]. Therefore, a trust-worthy relationship with doctors might be an important supportive factor for PLWHA's psychological health and clinical treatment. Nevertheless, this study found that $45.3 \%$ of the participants did not have a high level of trust-in-doctor. This might be partly associated with deteriorative patient-doctor relationships in China. Moreover, discriminatory attitudes and lack of willingness to interact with AIDS patients displayed by Chinese health professionals might also deteriorate patients' trust [64]. Nowadays, the majority of providers of HIV-related services in China are clinicians who have not been trained in the provision of psychological interventions [65], which may directly interfere with their ability to meet the multidimensional needs of PLWHA. Based on these facts, there is an urgent need to establish comprehensive treatment and care services including clinical treatment, psychological care and social support for PLWHA in China. This could be potentially valuable for reducing hostility among PLWHA.

Further into the protective factors for hostility, among the sociodemographic characteristics, higher per capita household income was a significant protective factor. Household income plays an important part in the economic and social stability of PLWHA [66]. However, HIV infection could lead to a decrease in household income, since patients cannot work as much as before, and some might have to quit or change their jobs $[67,68]$. A previous study showed that household income reduced on average by $16 \%$ after a member of the household was infected with HIV [69]. In our study, more than half the participants had a lower household income (less than $2000 \mathrm{CNY}$ per capita monthly) and more than half of the participants were at the age stage of earning the main salary in their family (30-49 years). However, the possibility of failing to provide for their family due to their reduced work ability may place great psychological burden on PLWHA, which may, in turn, increase their risk of hostility towards society. Policies aimed at maintaining the household income of PLWHA (e.g., by providing appropriate re-employment chances) should also be a priority in China.

Our study has several limitations. First, the data were collected through a self-reported questionnaire; therefore, recall bias and social desirability bias may exist. Second, as it was a cross-sectional study, we could not establish causal relationships based on the results. Third, our sample included only people who agreed to participate in this study, thus, findings in this sample might differ from those in PLWHA who refused. Fourth, the generalizability of the findings was limited because after the data cleaning process, we did not include non-Han and non-illiteracy PLWHA who failed to complete the questionnaire and this study was only conducted in one HIV-designated hospital in Heilongjiang. Further studies with a larger and more diverse sample and those that thoroughly analyze the mechanisms of various factors influencing hostility among PLWHA, are needed.

\section{Conclusions}

The prevalence of hostility among PLWHA in the present study was $17.0 \%$. Further, depression, perceived stigma, fear of dying, trust-in-doctor, and per capita household income were associated with hostility. Our findings highlighted the prominent influence of psychological, healthcare, and social factors on hostility among PLWHA, which are important for developing more targeted intervention strategies for reducing hostility among PLWHA. First, the psychological component of PLWHA should be incorporated into HIV/AIDS management guidelines, aiming at providing screening and appropriate care for psychological disorders, and consequently reducing PLWHA's negative beliefs about the disease and society. Second, to enhance PLWHA's trustin-doctor, in addition to provide better communication and more humanistic care, healthcare professionals also should be provided with specific educational programs to help improve their attitudes, knowledge and practices regarding HIV/AIDS. Third, there is an urgent need to establish comprehensive services including clinical treatment, psychological care and social support for PLWHA in China. Fourth, social interventions should focus on changing the social stigma against PLWHA by raising disease awareness, as well as providing more financial and medical assistance to PLWHA with financial problems.

\section{Abbreviations \\ AIDS: Acquired Immunodeficiency Syndrome; ART: Antiretroviral Therapy; BDC: Burns Depression Checklist; CNY: Chinese Yuan; HIV: Human Immunodeficiency Virus; MSM: Men Who Have Sex with Men; PLWHA: People Living With HIV/AIDS; SAS: Zung Self-Rating Anxiety Scale; WFPTS: The Wake Forest Physician Trust Scale; WHO: World Health Organization}

\section{Acknowledgments}

The authors thank the participants for completing the study questionnaire.

\section{Authors' contributions}

MMZ, BHL and TZ analyzed and interpreted the data, and drafted the original manuscript, and contributed equally as the first author of this article. QHW and LBL designed the study. YHH, WLN, CW, FXW and ML organized the survey and performed data collection. JX, JHW and XZ assisted with the literature review and contributed to the manuscript's revision. All authors approved the final manuscript for publication.

\section{Funding}

This study was supported by Key Think Tank in Heilongjiang Province and Think Tank of Public Health Security and Health Reform of Heilongjiang Province (ZKWT1013). The funders played no role in the design of the study and collection, analysis, and interpretation of data and in writing the manuscript. 


\section{Availability of data and materials}

The datasets are available from the corresponding author on reasonable request.

\section{Ethics approval and consent to participate}

This study was approved by the Research Ethics Committee of Harbin Medical University. Participants gave their written informed consent to confirm their involvement prior to data collection.

\section{Consent for publication}

Not applicable.

\section{Competing interests}

The authors declare that they have no competing interests.

\section{Author details}

'Department of Social Medicine, School of Health Management, Harbin Medical University, 157 Baojian Road, Nangang District, Harbin 150081, Heilongjiang, China. ${ }^{2}$ Department of Health Management, School of Public Health, Nantong University, 9 Seyuan Road, Chongchuan District, Nantong 226019, Jiangsu, China. ${ }^{3}$ The Second Affiliated Hospital of Harbin Medical University, 247 Xuefu Road, Nangang District, Harbin 150001, Heilongjiang, China. ${ }^{4}$ The First Affiliated Hospital of Harbin Medical University, 23 Youzheng Road, Nangang District, Harbin 150001, Heilongjiang, China. ${ }^{5}$ The Third People's Hospital of Shenzhen, 29 Bulan Road, Longgang District, Shenzhen 518100, China.

Received: 17 January 2019 Accepted: 21 August 2019

Published online: 29 August 2019

\section{References}

1. The Global HIV/AIDS Epidemic. In: Global Health Policy. KFF, Henry J Kaiser Family Foundation. 2018. https://www.kff.org/global-health-policy/factsheet/the-global-hivaids-epidemic/. Accessed 15 Oct 2018.

2. World Health Organization. HIV/AIDS: Data and statistics. 2018. http://www who.int/hiv/data/en/. Accessed 3 Oct 2018.

3. NCAIDS, NCSTD, China CDC. Update on the AIDS/STD epidemic in China in December 2017. Chinese J of AIDS \& STD. 2018;2:111.

4. NCAIDS, China CDC. Update on the AIDS/STD epidemic in China and main response in control and prevention in December 2012. Chinese J of AIDS \& STD. 2013;(2):85.

5. Crepaz N, Marks G. Are negative affective states associated with HIV sexual risk behaviors? A meta-analytic review. Health Psychol. 2001;20(4):291-9.

6. Sun W, Wu M, Qu P, Lu C, Wang L. Psychological well-being of people living with HIV/AIDS under the new epidemic characteristics in China and the risk factors: a population-based study. Int J Infect Dis. 2014;28:147-52.

7. Rueda S, Mitra S, Chen S, Gogolishvili D, Globerman J, Chambers L, et al. Examining the associations between HIV-related stigma and health outcomes in people living with HIV/AIDS: a series of meta-analyses. BMJ Open. 2016;6(7):e011453.

8. Saki M, Kermanshahi SMK, Mohammadi E, Mohraz M. Perception of patients with HIV/AIDS from stigma and discrimination. Iran Red Crescent Med J. 2015;17(6):e23638.

9. Kinyanda E, Hoskins S, Nakku J, Nawaz S, Patel V. The prevalence and characteristics of suicidality in HIV/AIDS as seen in an African population in Entebbe district. Uganda BMC Psychiatry. 2012;12:63.

10. Brinkley-Rubinstein L, Chadwick C, Graci M. The connection between serious life events, anti-retroviral adherence, and mental health among HIV-positive individuals in the Western cape. South Africa AIDS Care. 2013;25(12):1581-5.

11. Sebit MB, Tombe M, Siziya S, Balus S, Nkomo SD, Maramba P. Prevalence of HIV/AIDS and psychiatric disorders and their related risk factors among adults in Epworth. Zimbabwe East Afr Med J. 2003;80(10):503-12.

12. Gaynes BN, Pence BW, Atashili J, O'Donnell J, Kats D, Ndumbe PM. Prevalence and predictors of major depression in HIV-infected patients on antiretroviral therapy in Bamenda, a semi-urban center in Cameroon. PLoS One. 2012;7(7):e41699.

13. Bing EG, Burnam MA, Longshore D, Fleishman JA, Sherbourne CD, London $A S$, et al. Psychiatric disorders and drug use among human immunodeficiency virus-infected adults in the United States. Arch Gen Psychiatry. 2001;58(8):721-8.
14. Birkley EL, Eckhardt Cl. Anger, hostility, internalizing negative emotions, and intimate partner violence perpetration: a meta-analytic review. Clin Psychol Rev. 2015;37:40-56.

15. Rezaei S, Taramian S, Kafie SM. Psychopathological dimensions in substance abusers with and without HIV/AIDS and healthy matched group. Addict Health. 2013:5(3-4):115-25.

16. Kang D, Zhu X, Fu J. Comparison on the SCL-90 scores among HIV/AIDS patients with different characteristics. Mod Prev Med. 2010;37(2):291-3.

17. Staicu ML, Cuțov M. Anger and health risk behaviors. J Med Life. 2010;3(4):372-5.

18. Balta G, Karachailos T, Tsikrikas T, Angelopoulos NV. Alexithymia, hostility and depression in patients suffering from somatic diseases. Int J New Tech Res. 2016;2(8):1-4.

19. Wong JM, Na B, Regan MC, Whooley MA. Hostility, health behaviors, and risk of recurrent events in patients with stable coronary heart disease: findings from the heart and soul study. J Am Heart Assoc. 2013;2(5): e000052.

20. Graham JE, Robles TF, Kiecolt-Glaser JK, Malarkey WB, Bissell MG, Glaser R. Hostility and pain are related to inflammation in older adults. Brain Behav Immun. 2006;20(4):389-400.

21. Suarez EC, Lewis JG, Krishnan RR, Young KH. Enhanced expression of cytokines and chemokines by blood monocytes to in vitro lipopolysaccharide stimulation are associated with hostility and severity of depressive symptoms in healthy women. Psychoneuroendocrinology. 2004;29(9):1119-28.

22. Ibañez GE, Purcell DW, Stall R, Parsons JT, Gómez CA. Sexual risk, substance use, and psychological distress in HIV-positive gay and bisexual men who also inject drugs. AIDS. 2005;19(Suppl 1):S49-55.

23. Christodoulou C, Efstathiou V, Ferentinos P, Poulios A, Papadopoulou A, Douzenis A. Comparative study of hostility in depressive patients with and without a suicide attempt history. Psychol Health Med. 2017;22(7):866-71.

24. Zhang X, Mo X, Tang Z, Qin Y, Su J, Li X, Liu Y, Lu C. Analysis of the results of structured interview about hostile psychology in AIDS patients. J Appl Prev Med. 2018;24(2):89-97.

25. Waldron JC, Scarpa A, Lorenzi J, White SW. Depression mediates the relationship between social performance impairment and hostility. Pers Indiv Differ. 2015;85:165-71.

26. Hidru TH, Wang F, Lolokote $\mathrm{S}$, Jia $Y$, Chen $M$, Tong W, et al. Associated factors of self-reported psychopathology and health related quality of life among men who have sex with men (MSM) with HIV/AIDS in Dalian, China: a pilot study. Infect Dis Poverty. 2016;5(1):108.

27. Yajun M. Development of a quality of life measure specific for Chinese people living with HIV/AIDS and assessment of quality of life of these people: Sichuan University; 2007.

28. Bruno Pedroso, Gustavo Luis Gutierrez, Edison Duarte, Luiz Alberto Pilatti and Claudia Tania Picinin (October 26th 2011). Quality of Life Assessment in People Living with HIV/AIDS: Clarifying the WHOQOL-HIV and WHOQOLHIV-Bref Instruments, Global View of HIV Infection, Vishwanath Venketaraman, IntechOpen, DOl: https://doi.org/10.5772/21435. Available from: https://www.intechopen.com/books/global-view-of-hiv-infection/ quality-of-life-assessment-in-people-living-with-hiv-aids-clarifying-thewhoqol-hiv-and-whoqol-hiv-b.

29. Ming Z, Prybylski D, Cheng F, Airawanwat R, Zhu Q, Liu W, Huang S. Twoyear prospective cohort study on quality of life outcomes among people living with HIV after initiation of antiretroviral therapy in Guangxi. China J Assoc Nurses AIDS Care. 2014;25(6):603-13.

30. Qu L. Study on living situation of HIV/AIDS patients: Huazhong University of Science and Technology; 2008.

31. Quintin E, Bélanger C, Lamontagne V. A single-case experiment for an innovative cognitive behavioral treatment of auditory hallucinations and delusions in schizophrenia. Int J Psychological Stud. 2012;4(1):114-21.

32. Chen J, Liang J, Ou J, Cai W. Mental health in adults with sudden sensorineural hearing loss: an assessment of depressive symptoms and its correlates. J Psychosom Res. 2013;75(1):72-4.

33. Philip B. Analysing the politics of self-help books on depression. J Sociol. 2009:45(2):151-68.

34. Zung WW. A rating instrument for anxiety disorders. Psychosomatics. 1971;12(6):371-9.

35. Lei M, Li C, Xiao X, Qiu J, Dai Y, Zhang Q. Evaluation of the psychometric properties of the Chinese version of the resilience scale in Wenchuan earthquake survivors. Compr Psychiatry. 2012;53(5):616-22. 
36. Gong Y, Han T, Chen W, Dib HH, Yang G, Zhuang R, et al. Prevalence of anxiety and depressive symptoms and related risk factors among physicians in China: a cross-sectional study. PLoS One. 2014;9(7):e103242.

37. Hall MA, Zheng B, Dugan E, Camacho F, Kidd KE, Mishra A, et al. Measuring patient' trust in their primary care providers. Med Care Res Rev. 2002;59(3):293-318.

38. Dong H, Bao Y. Reliability and validity of the Chinese version of wake Forest physician trust scale. Chin Ment Health J. 2012;26(03):171-5.

39. Sun J. Study on living situation of people living with HIV/AIDS in Suizhou city of Hubei province: Huazhong University of Science and Technology; 2006.

40. Oforwe CE, Oforwe C. Psychological disorders among human immunodeficiency virus-infected adults in southern Nigeria. Afr J Reprod Health. 2013;17(4Spec No):177-182.

41. Thompson SC, Nanni C, Levine A. The stressors and stress of being HIVpositive. AIDS Care. 1996;8(1):5-14.

42. Cuihong X. Overview of psychological care for AIDS patients. Public Medical Forum Magazine. 2015;15:2084-6.

43. Cherilyn RB, Gary M, Crepaz N. Attributions about One' s HIV infection and unsafe sex in seropositive men who have sex with men. AIDS Behav. 2001:5(3):283-9.

44. Clement U, Schönnesson LN. Subjective HIV attribution theories, coping and psychological functioning among homosexual men with HIV. AIDS Care. 1998;10(3):355-63.

45. Crum-Cianflone NF, Roediger MP, Moore DJ, Hale B, Weintrob A, Ganesan A, et al. Prevalence and factors associated with sleep disturbances among early-treated HIV-infected persons. Clin Infect Dis. 2012;54(10):1485-94.

46. Tate D, Paul RH, Flanigan TP, Tashima K, Nash J, Adair C, et al. The impact of apathy and depression on quality of life in patients infected with HIV. AIDS Patient Care STDs. 2003;17(3):115-20.

47. Niu L, Luo D, Liu Y, Silenzio VMB, Xiao S. The mental health of people living with HIV in China, 1998-2014: a systematic review. PLoS One. 2016;11(4):e0153489.

48. Judd LL, Schettler PJ, Coryell W, Akiskal HS, Fiedorowicz JG. Overt irritability/ anger in unipolar major depressive episodes: past and current characteristics and implications for long-term course. JAMA Psychiatry. 2013;70(11):1171-80.

49. Finman $\mathrm{R}$, Berkowitz $\mathrm{L}$. Some factors influencing the effect of depressed mood on anger and overt hostility toward another. J Res Pers. 1989;23(1):70-84.

50. Fava M, Hwang I, Rush AJ, Sampson N, Walters EE, Kessler RC. The importance of irritability as a symptom of major depressive disorder: results from the National Comorbidity Survey Replication. Mol Psychiatry. 2010;15(8):856-67.

51. Cassiello-Robbins C, Barlow DH. Anger: the unrecognized emotion in emotional disorders. Clin Psychol Sci Pract. 2016;23(1):66-85.

52. Gross JJ, Jazaieri H. Emotion, emotion regulation, and psychopathology: an affective science perspective. Clin Psychol Sci. 2014;2(4):387-401.

53. Zeng C, Li L, Hong YA, Zhang H, Babbitt AW, Liu C, et al. A structural equation model of perceived and internalized stigma, depression, and suicidal status among people living with HIV/AIDS. BMC Public Health. 2018;18(1):138.

54. Wu X, Chen J, Huang H, Liu Z, Li X, Wang H. Perceived stigma, medical social support and quality of life among people living with HIV/AIDS in Hunan. China Appl Nurs Res. 2015;28(2):169-74.

55. Zuxiang Z, Minyang X, Manhong J, Hongbing L, Jingyuan M, Liru F, Xuehua $L$, Lijun S. Self-perceived stigma and related factors in people with human immunodeficiency virus in border area. Chinese Mental Health J. 2014:09:646-50.

56. Zhang X, Zhu H, Li S. Quality of life, Social Support and Aggression among People Living with HIV/AIDS in Kunming Chinese. J Health Psychol. 2015;9: 1307-10.

57. Maughan-Brown B. Stigma rises despite antiretroviral roll-out: a longitudinal analysis in South Africa. Soc Sci Med. 2010;70(3):368-74.

58. Malinauskaite I, Slapikas R, Courvoisier D, Mach F, Gencer B. The fear of dying and occurrence of posttraumatic stress symptoms after an acute coronary syndrome: a prospective observational study. J Health Psychol. 2017;22(2):208-17.

59. Whitehead DL, Strike P, Perkins-Porras L, Steptoe A. Frequency of distress and fear of dying during acute coronary syndromes and consequences for adaptation. Am J Cardiol. 2005;96(11):1512-6.
60. Zea MAC, Reisen CA, Poppen PJ, Bianchi FT, Echeverry JJ. Disclosure of HIV status and psychological well-being among Latino gay and bisexual men. AIDS and Behav. 2005;9(1):15-26.

61. Hult JR, Wrubel J, Bränström R, Acree M, Moskowitz JT. Disclosure and nondisclosure among people newly diagnosed with HIV: an analysis from a stress and coping perspective. AIDS Patient Care STDs. 2012;26(3):181-90.

62. Holt R, Court P, Vedhara K, Nott KH, Holmes J, Snow MH. The role of disclosure in coping with HIV infection. AIDS Care. 1998;10(1):49-60.

63. Carr GS. Negotiating trust: a grounded theory study of interpersonal relationships between persons living with HIV/AIDS and their primary health care providers. J Assoc Nurse AIDS Care. 2001;12(2):35-43.

64. Li L, Wu Z, Zhao Y, Lin C, Detels R, Wu S. Using case vignettes to measure HIV-related stigma among health professionals in China. Int J Epidemiol. 2007;36(1):178-84.

65. Lu W, Zeng G, Luo J, Duo S, Xing G, Guo-Wei D, et al. HIV transmission risk among serodiscordant couples: a retrospective study of former plasma donors in Henan. China J Acquir Immune Defic Syndr. 2010;55(2):232-8.

66. Bhatia MS, Munjal S. Prevalence of depression in people living with HIV/ AIDS undergoing ART and Factors associated with it. J Clin Diagn Res. 2014;8(10):WC01-4.

67. Bachmann MO, Booysen FLR. Health and economic impact of HIV/AIDS on south African households: a cohort study. BMC Public Health. 2003:3(1):14.

68. Stewart KE, Cianfrini LR, Walker JF. Stress, social support and housing are related to health status among HIV-positive persons in the deep south of the United States. AIDS Care. 2005;17(3):350-8.

69. Maikang L, Jianhua Y, Xiyuan X, Siyu J, Edmund S, Yuhua G, Chun C, Tap J, Yuchen D, Qiang W, et al. Study of HIV/AIDS impact on individual and household conditions in five provinces of China. Chinese J AIDS \& STD. 2009:04:341-4

\section{Publisher's Note}

Springer Nature remains neutral with regard to jurisdictional claims in published maps and institutional affiliations.
Ready to submit your research? Choose BMC and benefit from:

- fast, convenient online submission

- thorough peer review by experienced researchers in your field

- rapid publication on acceptance

- support for research data, including large and complex data types

- gold Open Access which fosters wider collaboration and increased citations

- maximum visibility for your research: over $100 \mathrm{M}$ website views per year

At BMC, research is always in progress.

Learn more biomedcentral.com/submissions 